\title{
Perceived stress and well-being amongst Dental Hygiene and Dental Therapy Students
}

\section{Harris, ${ }^{* 1}$ J.C. Wilson, ${ }^{2}$ S. Holmes ${ }^{3}$ and D.R. Radford $^{4}$}

${ }^{* 1}$ PhD student; University of Portsmouth Dental Academy

${ }^{2}$ Reader in Applied Psychology; University of Portsmouth

${ }^{3}$ Professor of Dental Education; University of Portsmouth Dental Academy

${ }^{4}$ Reader Hon Consultant, Integrated Dental Education and Multi-Professional Care; King's College London Dental Institute and the University of Portsmouth Dental Academy

Correspondence to: Marina Harris*

University of Portsmouth, Faculty of Science, William Beatty Building, Hampshire Terrace, Portsmouth. PO1, 2QG.

marina.harris@myport.ac.uk 


\section{ABSTRACT}

Aims: To explore Dental Hygiene and Dental Therapy Students' (DHDTS) perception of stress and well-being during their undergraduate education and establish base-line data for further studies of this group of dental professionals.

Subjects and Methods: A questionnaire was distributed to Years 1, 2 and 3 DHDTS and final year outreach Dental Students (DS) (as a comparison group), at the University of Portsmouth Dental Academy (UPDA), during summer 2015. Data were collected on students' perception of levels of stress and well-being. Statistical analyses were undertaken using SPSS ${ }^{\mathrm{TM}}$ software. Mann-Whitney $U$ tests with Bonferroni corrections were used and the level for a statistically significant difference was set at $p<0.002$. Results: A response rate of $81 \%$ (DHDTS) and $85 \%$ (DS) was achieved. Clinical factors and academic work were perceived as stressful for both DHDTS and DS, with no significant difference between the groups. The majority of respondents reported levels of depression, anxiety, and stress to be within the normal range. All students reported high levels of positive well-being, with DHDTS scoring significantly higher than DS in the dimensions of personal growth, purpose in life, self-acceptance and positive relations with others $(p<0.002)$. Conclusions: DHDTS and DS identified sources of stress within their undergraduate education, but also perceived themselves as positively-functioning individuals. 


\section{INTRODUCTION}

For Dental Students (DS), the dental school curriculum and environment is known to be highly demanding and a stressful learning experience. ${ }^{1}$ A number of studies have demonstrated the impact of stress on DS, and the perceived sources of stress in diverse academic settings. ${ }^{2,3,4}$ For example, two recent systematic reviews concluded that researchers consistently reported examinations and grades, workload, patient care, and graduation requirements amongst the top stressprovoking factors. ${ }^{5,6}$ Some DS reported feeling overwhelmed by their experience in dental school to the extent that their physical and mental health, as well as their social life, was negatively affected. ${ }^{7}$

Other members of the dental team are educated in a similar environment to that of DS. Dental Hygiene and Therapy Students (DHDTS) undertake a degree or a diploma programme, which requires the development of theoretical and critical thinking skills, in parallel with acquiring the clinical skills, to carry out relatively complex clinical operative procedures. Similar to DS education, DHDTS in the UK need to have competency in a range of skills, within their scope of practice, ${ }^{8}$ in order to qualify and register as 'safe beginners' after graduation. ${ }^{9}$ Therefore, after only up to 3 years of education (4 years in Scotland), compared to 5 years for DS, and with very limited access to post qualification placement, ${ }^{10}$ DHDTs on graduation, have to be confident, competent, and resilient, so that they can manage patients independently. However, DHDTS stress levels, unlike DS, have yet to be explored. Furthermore, as their responsibilities are increasing with a change in legislation, ${ }^{11}$ their well-being needs to be investigated.

In the future, DHDTs, according to the Centre for Workforce Intelligence, could be providing $40-50 \%$ of oral health care by the year $2025,{ }^{12}$ which is a more conservative estimate compared to other studies which puts this figure at approximately $70 \%{ }^{13,14}$ It is thus argued, a profession that contributes significantly to the oral care provision of the public is worthy of in-depth study regarding stress and well-being.

Psychological stress occurs when a person appraises a situation as exceeding their resources to cope and endangering their well-being. ${ }^{15}$ The stress response ('fight', 'flight', 'freeze') is a mechanism adapted for dealing with short-term physical 
emergencies. ${ }^{16}$ For such short-term emergencies the stress response is vital, but in the face of chronic stress, the constant demand to the body system is considered to be detrimental to health.

Whilst the detrimental effects of stress may be significant, recent research has shown that stress can also have a positive effect on physiological functioning. ${ }^{17}$ More specifically, by positively reappraising stress as a tool to aid performance, participants in one study demonstrated a more adaptive physiological response to stress; as measured by greater cardiac output and less vasoconstriction, compared with participants assigned in other conditions. ${ }^{17,18}$ In another study, Crumb et al demonstrated how the meaning of stress can alter the evaluation of the stress as a challenge (enhancing) rather than a threat (debilitating). In this instance, individuals are able to create an adaptive stress response by modifying the amount of cortisol that is released. ${ }^{19}$ Similarly, other research also shows how potentially stressful events such as parenting, intimate relationships and work achievements, when described as being profoundly meaningful, as opposed to merely stressful, give lives structure and purpose. ${ }^{20}$

Most research into stress in dental undergraduate students has equated psychological well-being with the presence or absence of stress, or psychological disorders such as depression. ${ }^{21,22,23}$ However, research has shown that there are multiple dimensions which contribute to a sense of positive psychological well-being. ${ }^{24,25}$ Positively-functioning individuals establish goals, direction, and purpose, which give them a sense of meaning in life. They are self-determined, and will take advantage of environmental opportunities (even if they are stressful) to continue to develop and grow. ${ }^{24,25}$

Meaningful goal pursuit is central to Snyder's theory of hope. ${ }^{26}$ Specifically, hope is defined as "the process of thinking about one's goals, along with the motivation to move towards those goals (agency), and the ways to achieve those goals (pathways)", regardless of the ease or the difficulty of obtaining them. ${ }^{26,27,28}$ Individuals also use goal setting as a means for increasing their engagement in valued-living; moreover, it is often the journey to goals, rather than the destination, that gives fulfilment. ${ }^{29}$ Values are personally chosen life directions, based on 
subjectively experienced principles which guide our behaviour. They are not about what 'others expect' us to do, but are about what we 'want to do'. ${ }^{29}$

In summary, previous research into stress amongst dental undergraduates has focused on the negative aspects of stress, and ignored measurements of positive well-being (such as goals and values). Furthermore, it has been exclusively targeted at the stressors experienced by the DS, and not included DHDTS, who follow very similar clinical training patterns. Accordingly, the aims of this study, to address this gap, were:

1. To explore the current sources of stress and well-being in DHDTS.

2. To include a comparison group of DS, so comparisons could be made with existing research into stress and well-being during dental student education.

3. To establish baseline data that will facilitate further research into the stress and well-being of DHDTS.

\section{SUBJECTS AND METHODS}

Ethical approval was gained from the University of Portsmouth Research Ethics Committee, and an anonymous, self-reported online questionnaire (Figure 1) was administered to 72 DHDTS (Years 1, 2 \& 3) and 80 Year 5 outreach DS (as a comparison group) at the University of Portsmouth Dental Academy (UPDA) in June $2015 .^{30}$ Completion of the survey was taken as consent to participate in the study. The survey was distributed over a four-week period in June 2015, representing the end of the examination period and the completion of the academic year. Qualtrics ${ }^{\mathrm{TM}}$ software used for the survey captured the students' year of study and age. Gender was not captured, as this would identify the very small number of male DHDTS. The survey consisted of five well-used measurement instruments, which all had excellent reliability and validity, and included the: Dental Environment Stress questionnaire (DES); Depression Anxiety Stress Scales (DASS-21); Scales of Psychological WellBeing (SPWB); Valuing Questionnaire (VQ); and the Adult Hope Scale (AHS).

The DES ${ }^{31}$ was chosen as it is the most widely used measurement in the dental setting, within the existing literature. A modified version was used, ${ }^{32}$ consisting of thirty-nine items describing stressors specifically relating to dental undergraduate 
training. The response to each item was rated on a five-point scale: $0=$ not pertinent, 1 = not stressful, 2 = slightly stressful, $3=$ moderately stressful and 4 = very stressful. The mean score was calculated for each item of the DES to evaluate stress levels and a total score was calculated by summing all responses. The items were grouped into five stressor domains: living accommodation, personal factors, educational environment, academic work and clinical factors.

The DASS $-21,{ }^{33}$ a shorter version of the full survey (DASS - 42), was adopted. It consisted of three self-reporting scales constructed to measure the negative emotional states of depression, anxiety and stress. Each of these contained 7 items. Participants responded using a 4-point severity and frequency scale to rate the extent to which they had experienced each over the past week: $0=$ did not apply to me at all, 1 = applied to me to some degree, or some of the time, 2 = applied to me to a considerable degree, or a good part of the time and $3=$ applied to me very much, or most of the time. Separate scores for depression, anxiety and stress were calculated by summing the scores for each. These were then multiplied by 2 to fit with the DASS - 42 scale. Figure 2 shows the authors' recommended cut-off scores for the labels of 'normal', 'moderate' and 'severe', in relation to depression, anxiety and stress.

The SPWB, ${ }^{24}$ six self-reporting scales consisting of 14 items, was selected to measure the dimensions of autonomy, environmental mastery, personal growth, positive relations with others, purpose in life, and self-acceptance. The response to each item was rated on a six-point scale: 1 = strongly disagree, 2 = moderately disagree, 3 = slightly disagree, 4 = slightly agree, 5 = moderately agree and $6=$ strongly agree. There is no specific score for defining high or low well-being, therefore thresholds for 'pure' positive and negative scores were set at $>56$ and $<42$ respectively.

The VQ, ${ }^{29}$ a self-reporting 10-item scale, was adopted to measure the extent to which DHDTS (and comparatively DS) lived out their values across their life. The VQ was used to measure how much participants were living according to their personal values, rather than what their values were per se. This instrument was originally designed to track clients' progress towards living according to their values in Acceptance and Commitment Therapy $(\mathrm{ACT}),{ }^{34}$ but it is not client specific so can be 
used with the general population. Indeed, a very recent study has also used the VQ as one of the instruments in a survey of Australian undergraduate students. ${ }^{35}$ Participants responded using a six-point format ranging from $0=$ not at all true, through to $6=$ completely true. The 10 -item scale has 2 subscales: 5 items totalled which measures progress towards valued living and 5 items which measures obstruction towards valued living. Subscale scores were calculated by summing the scores of the 5 items in each sub-scale to get a score for the progress domain and a score for the obstruction domain.

Finally, the $\mathrm{AHS},{ }^{26}$ a self-reporting 12-item scale was selected. It consists of two subscales that measure 'agency' (goal-directed energy) and 'pathways' (planning to accomplish goals). Of the total 12 items, 4 measure agency and 4 measure pathway. The remaining 4 items are 'fillers'. Participants responded using an eight-point scale: 1 = definitely false, 2 = mostly false, 3 = somewhat false, 4 = slightly false, $5=$ slightly true, 6 = somewhat true, 7 = mostly true, 8 = definitely true. Individual scores for agency hope and pathway hope were calculated by summing the scores of the 4 items in each. There is no specific score defining high and low hope, however an early study by the author of the AHS, suggested that 'high hope' and 'low hope' equated to a combined agency and pathway score of $>60$ and $<35$ respectively. ${ }^{36}$

Statistical analysis carried out using SPSS v22 ${ }^{\mathrm{TM}}$ included frequency distributions, reliability analysis, and correlation analysis. The data were checked for normality, kurtosis and skew. Mann-Whitney $U$ tests with Bonferroni corrections were used to reduce the chances of obtaining false-positive results (type 1 errors) as multiple pair wise tests were performed on a single set of non-parametric data. The level for a statistically significant difference was set at $p<0.002$.

\section{RESULTS}

Cronbach's alpha ranged from .79 to .87 for all of the scales, except the DES where it was slightly lower at .68. The reliability of all the scales was within the acceptable limits. The response rate was $81 \%$ for DHDTs $(n=58)$, and $85 \%$ for DS $(n=68)$. The mean age for DHDTS was 25 years, with a range of 19 to 38 years. The mean age for DS was 23 years, with a range of 21 to 32 years. 
The $81 \%$ and $85 \%$ response rate for DHDTS and DS respectively, represented a good response to the first investigation of DHDTS perceived sources of stress and well-being. Out of the 58 DHDTS who responded, 53 provided useable data.

Table 1 compares the domain-specific sources of stress mean DES scores for DHDTS and DS. There were no statistically significant differences between the DHDTS and the DS for any of the domains of the DES. Academic work and clinical factors were reported stressful by both groups.

Table 2 presents the highest individual item stressors defined by DHDTS for each year of study. Examinations were reported as a high source of stress across all of the Years. They were however the only high source of stress for Year 2 DHDTS and Year 5 DS. Year 1 and Year 3 DHDTS listed the same three top sources of stress as being: fear of failing course/year, examinations, and fear of being able to catch up if falling behind. Fear of failing the course/year scored the highest. Year 3 DHDTS additionally equally listed the difference in opinion between clinical staff in third place.

Table 3 shows the dimensions of SPWB mean scores for DHDTS and DS. Both DHDTS and DS mean scores were above the threshold for a negative score $(<42)$, with a trend towards the threshold of a positive score $(>56)$, for both groups, in all dimensions, except purpose in life. Four out of the six dimensions were statistically significant $(p<0.002)$, with DHDTS scoring higher than the DS in personal growth, purpose in life, positive relations with others and self-acceptance.

Table 4 shows the mean scores for the DASS-21, AHS and VQ for the DHDTS and DS. The majority of depression, anxiety and stress scores for both groups were within the recommended cut-off scores for the label 'normal' (0-9 for depression, 0-7 for anxiety, 0-14 for stress). ${ }^{33}$ Both DHDTS and DS reported fairly high levels of agency hope, pathway hope ${ }^{36}$, and progress towards values; all also reported fairly low levels of obstruction towards values. There was no statistical difference between the two groups.

\section{DISCUSSION}


The reported domain-specific sources of stress mean DES scores and individual item stressor scores showed similar trends for both DHDTS and DS. These were comparable to reported findings of what students, in diverse educational settings, had previously reported in studies as being their main sources of stress. ${ }^{2,3,4}$

Living accommodation, personal factors, and the educational environment were not particularly stressful DES domains for either DHDTS or the DS (Table 1), and corresponded with the existing literature..$^{2,3,4}$ The two domains of academic work and clinical factors, which included items such as examinations, fear of failing, and completing clinical requirements, were also similar to other studies in which dental students reported them to be highly stressful. ${ }^{5,6}$ Moving beyond the existing literature, this study showed a trend that DHDTS found academic work (21.43 out of 32 ) more stressful than clinical factors (20.70 out of 36 ), but it was not statistically significant.

Data also showed that the educational programme per se was perceived by DHDTS as highly stressful, but specifically the academic components (Table 2). The high individual item stressors reported by Year 1 DHDTS demonstrated that they recognised the high level of attainment required to attain a professional qualification and practice clinical dentistry.

In Year 2, DHDTS reported only one high level source of stress (examinations), but then increased again in Year 3, to the same sources, and similar levels, as in Year 1. This trend of academic stress may just reflect the nature of this particular DHDT training programme, which is an honours degree and places equal emphasis on academic assessment, as well as clinical attainment, throughout all the three years of training. There may also have been a level of under-confidence of academic ability for a percentage of DHDTS, who have been in the work place, and have returned to study after being away from it for a considerable length of time. Furthermore, year 1 and year 3 are entry and exit points respectively, and this may have increased the stress perceptions of students in comparison to the middle year.

Transition from preclinical to clinical work was not reported as being highly stressful for Year 2 DHDTS. This finding is inconsistent with that from other studies of DS which have looked at DES individual item stressors across each year of study and found that Year 3 DS reported the same transition as being highly stressful. ${ }^{5,32}$ 
Unlike some dental undergraduate programmes, that focus on theory and laboratorybased skills education in the first two years, the UPDA curriculum introduces clinical experience at a very early stage in Year 1 (after 3 months), which may have been a contributing factor which lessened the perceived stress of transition to practice for the studied DHDTS.

Likewise, in contrast to the findings of previous studies, ${ }^{5,6}$ clinical factors such as completing clinical requirements and shortage of allocated clinical time were not reported as the highest stressor for either DHDTS or DS in this research. Historically, within the literature these items have been reported as highly stressful, particularly to DS in their final year of study. ${ }^{5,6}$ Clinical factors may be less stressful than academic work for the DHDTS studied, because a considerable percentage of them had previous experience working as dental nurses (DNs) in general dental practice. In this respect, they were likely to have the maturity to cope with stressful patient management issues and already had a level of clinical orientation.

Both DHDTS and DS reported scores of psychological well-being that were indicative of students who were positively-functioning individuals (Table 3). Measures of self-determination (autonomy), and the ability to take advantage of opportunities (environmental mastery), showed similar trends for both groups, and are dimensions that bring a sense of meaning to life. ${ }^{20,24,25}$ They are also attributes and qualities that hold high importance to the professional identity of future clinicians. However, the measures of continual development and openness to experience (personal growth), goals and intentions (purpose in life), the ability to respond to other individuals (positive relations with others) and a positive attitude to oneself and others (self-acceptance), were significantly higher $(p<0.002)$ for the DHDTS than the DS. The scores for DHDTS in the dimensions of personal growth, purpose in life and self-acceptance, were similar to, or higher than, scores rated as 'high well-being' in a recent study examining physical activity levels and psychological well-being amongst 700 university students. ${ }^{37}$ It was not too surprising that there was a difference in scores for personal growth and positive relations with others as DHDT training is female-dominated, and studies have shown that personal growth and positive relations are particular dimensions which are more central to female conceptions of their development, than they are to males. ${ }^{24,25}$ The difference in purpose in life 
scores between the two groups is unclear. It may be that the more prestigious and higher earning career of dentistry invites those who are initially more career driven "I want to be a dentist" than DHDTs who are likely to be seeking career progression. Self-acceptance is associated with self-confidence and self-reliance, which are attributes that are developed with age and experience. The mean age of the DHDTS (25yrs) was two years older than the DS (23yrs), and the scores for self-acceptance reflected more self-confidence in the mature DHDTS than that of the younger DS.

The reported levels of agency hope and pathway hope (Table 4), showed a tendency for both DHDTS and DS to embark on meaningful goal pursuit, and to have plans to meet those goals. Previous studies have shown that students who score highly in these sub-scales are more likely to focus on success rather than failure. Moreover, they can sustain their motivation by utilising goal setting as a challenge for high academic achievement, even under circumstances of stress. ${ }^{26,38}$

It was reassuring that the majority of DHDTS and DS did not report levels of depression, anxiety or stress mean scores that would generally be considered outside of the normal- range ${ }^{33}$ (Table 4). Some studies have examined psychological morbidity in association with dental undergraduate stress (e.g. depressive symptoms), but different instruments have been used across the studies, and so it is difficult to make comparisons. ${ }^{21,22,23}$

Compared to a recent study which measured students' progress to values, ${ }^{35}$ the higher scores for progress towards values, and the low scores for obstruction to values for both groups (Table 4), showed that DHDTS and the DS were students who reported to be living according to their values. ${ }^{29}$ Although valued living is a subjective experience, 'wanting to do' the right thing, in the best interest of the patient for example, is an attribute of professionalism, ${ }^{9}$ and is another quality that is of critical importance to a future clinician:

\section{CONCLUSIONS}

This study was an investigation into the perceived sources of stress and well-being in DHDTS. Through surveying a group of DS studying at the same institution, at the same time, comparisons could be made with previous studies. This study found that 
the reported sources of stress for this sample of DHDTS (and DS), showed similar trends to the existing studies of DS undergraduate education. However, moving beyond the existing literature, it also assessed positive well-being.

This study showed that DHDT students and DS reported high levels of perceived stress, specifically in the academic domain of the DES. However, at the same time, the majority in both groups reported high levels of positive psychological well-being and normal ranges of stress, anxiety and depression. In contrast to previous studies, which have made the assumption that stress in dental undergraduate training is debilitating, this study showed that DHDT and DS undergraduate training was indeed perceived as academically stressful, however, at the same time, the students also reported to be positively-functioning individuals. 


\section{REFERENCES}

1. Al-Samadani $\mathrm{KH}, \mathrm{Al}$-Dharrab A. The perception of stress among clinical dental students. World J Dent 2013; 4: 24-28.

2. Humphris G, Blinkhorn A, Freeman R, et al. Psychological stress in undergraduate dental students: baseline results from seven European dental schools. Eur J Dent Educ 2002; 6: 22-29.

3. Divaris K, Barlow P J, Chendea S A, Cheong W S, Dounis A, Dragan I F, Vrazic D. The academic environment; the students' perspective. Eur J Dent Educ 2008; 12: 120-130.

4. Gorter R, Hammen S, Freeman R, Murtomaa H, Blinkhorn A, Humphris G. Psychological stress and health in undergraduate dental students: fifth year outcomes compared with first year baseline results from five European dental schools. Eur J Dent Educ 2008; 12: 61-68.

5. Alzahem A M, Alaujan A H, Van der Molen H T, Schmidt H G, Zamakhshary M H. Stress amongst dental students: a systematic review. Eur J Dent Educ 2011; 15: 818.

6. Elani H W, Allison P J, Kumar R A, et al. A systematic review of stress in dental students. J Dent Educ 2014; 78: 226-242.

7. Dahan H, Bedos C. A typology of dental students according to their experience of stress: a qualitative study. J Dent Educ 2010; 74: 95-103.

8. General Dental Council. Scope of practice. 2013. Online information available at http://www.gdc-

uk.org/Dentalprofessionals/Standards/Documents/ScopeofpracticeSeptember2013 [3].pdf(accessed May 2016).

9. General Dental Council. Preparing for Practice (revised 2015). Online information available at http://www.gdc-uk.org/About us/Education/Documents/Preparing for Practice (revised 2015) pdf(accessed May 2016).

10.Clow R, Mehra S. Evaluation of vocational training of dentists in three different regions. Br Dent J 2006; 201: 774-778.

11. General Dental Council. Direct Access guidance. 2014. Online information available at http://www.gdc-

uk.org/Newsandpublications/factsandfigures/Documents/DirectAccessguidanceMay 2014.pdf(accessed May 2016).

12. Centre for Workforce Intelligence. Securing the future workforce supply:

Dentalcare professionals' stocktake. London: Mouchel Management Consulting Ltd, 2014. 
13. Wanyonyi K I, Radford D R, Harper P R, Gallagher J E. Alternative scenarios: harnessing mid-level providers and evidence-based practice in primary dental care in England through operational research. Hum Resour Health 2015; 13:78

14. Evans C, Chestnutt, I G, Chadwick, B L. The potential for delegation of clinical care in general dental practice. Br Dent J 2007; 203: 695-699

15. Lazarus R S, Folkman S. Stress, appraisal, and coping. New York: Springer Publishing Company, 1984

16. Sapolsky R M. Why zebras don't get ulcers: the acclaimed guide to stress, stress-related diseases, and coping. $3^{\text {rd }}$ ed. New York: St. Martin's press, 2004.

17. Jamieson J P, Mendes W B, Nock M K. Improving acute stress responses: the power of reappraisal. Current Directions in Psychol Sci 2013; 22: 51-56.

18. Jamieson J P, Nock, M K, Mendes W B. Mind over matter: reappraising arousal improves cardiovascular and cognitive responses to stress. J Exp Psychol Gen 2012; 141: 417-422

19. Crum A J, Salovey P, Achor S. Rethinking stress: the role of mindsets in determining the stress response. J Pers Soc Psychol 2013; 104: 716-733.

20. Baumeister R F, Vohs K D, Aaker J L, Garbinsky E N. Some key differences between a happy life and a meaningful life. J Pos Psychol 2013; 8: 505-516.

21. Silverstein S T, Kritz-Silverstein D. A longitudinal study of stress in first-year dental students. J Dent Educ 2010; 74: 836-848.

22. Laurence B, Williams C, Eiland D. Depressive symptoms, stress, and social support among dental students at a historically black college and university. $J$ American College HIth 2009; 58: 65-63.

23. Abu-Ghazaleh S B, Rajab L D, Sonbol H N. Psychological stress among dental students at the University of Jordan. J Dent Educ 2011; 75: 1107-1114.

24. Ryff C D. Happiness is everything, or is it? Explorations on the meaning of psychological well-being. J Pers Soc Psychol 1989a; 57: 1069-1081.

25. Ryff C D. Beyond Ponce de Leon and life satisfaction: new directions in quest of successful ageing. Int J Behav Develop 1989b; 12: 35-55.

26. Snyder C R, Harris C, Anderson J R, Holleran S A, Irving L M, Sigmon S T, Yoshinobu L, Gibb J, Langelle C, Harney P. The will and the ways: development and validation of an individual-differences measure of hope. J Pers Soc Psychol 1991; 60: $570-585$.

27. Snyder C R. Conceptualising, measuring, and nurturing hope. J Couns Dev 1995; 73: 355-360. 
28. Snyder C R, Cheavens J, Sympson S C. Hope: an individual motive for social commerce. Group Dymanics: Theory, Research, and Practice 1997; 1: 107-118

29. Smout M, Davies M, Burns N, Christie A. Development of the valuing questionnaire (VQ). J Context Behav Sci 2014; 3: 164-172.

30. Radford D R, Holmes S, Dunne S M, Woolford M J. Outreach clinical education; the Portsmouth experience. A four year follow up study. Eu J Dent Educ 2015; doi: 10.1111/eje.12153.

31. Garbee W H, Zucker S B, Selby G R. Perceived sources of stress among dental students. J Am Dent Assoc 1980; 100: 853-857.

32. Naidu R S, Adams J S, Simeon D Persad S. Sources of stress and psychological disturbance among dental students in the West Indies. J Dent Educ 2002; 66: 10211030.

33. Lovibond S H and Lovibond P F. Manual for the Depression Anxiety Stress Scales. $2^{\text {nd }}$ ed. Sydney: Psychology Foundation, 1995.

34. Dahl J C, Plumb J C, Stewart I, Lungdren T. The art and science of valuing in psychotherapy: Helping clients discover, explore, and commit to valued action using acceptance and commitment therapy. Oakland, CA: New Harbinger, 2009.

35. Fischer T D, Smout M F, Delfabbro P H. The relationship between psychological flexibility, early maladaptive schemas, perceived parenting and psychopathology. $J$ Contex Behav Sci 2016; 5: 169-177.

36. Snyder C R, LaPointe A B, Crowson J J, Early S E. Preferences of high and low hope people for self-referential input. Cognition and Emotion 1998; 12: 807-823.

37. Yerlisu Lapa, T. Physical activity levels and psychological well-being: A case study of university students. Procedia - Soc Behav Sci 2015; 186: 739-743.

38. Snyder C R, Shorey H S, Cheavens J, Mann Pulvers K, Adams V H, Wiklund C. Hope and academic success in college. J Educ Psychol 2002; 4: 820-826. 
Table 1. Domain-specific sources of stress mean DES scores for DHDTs and DS

\begin{tabular}{|l|l|l|l|}
\hline $\begin{array}{l}\text { DES Domain (max } \\
\text { score within each } \\
\text { domain) }\end{array}$ & $\begin{array}{l}\text { Mean (SD) } \\
\text { DHDT (n=58) }\end{array}$ & $\begin{array}{l}\text { Mean (SD) } \\
\text { DS (n=62) }\end{array}$ & $p$ value \\
\hline $\begin{array}{l}\text { Living } \\
\text { accommodation (16) }\end{array}$ & $7.67(3.93)$ & $6.69(2.70)$ & 0.108 \\
\hline Personal factors (52) & $18.58(7.77)$ & $17.40(8.05)$ & 0.499 \\
\hline $\begin{array}{l}\text { Education } \\
\text { environment (20) }\end{array}$ & $7.32(2.65)$ & $8.86(3.40)$ & 0.006 \\
\hline Academic work (32) & $21.43(5.50)$ & $18.68(5.44)$ & 0.003 \\
\hline Clinical factors (36) & $20.70(6.48)$ & $18.09(6.46)$ & 0.046 \\
\hline
\end{tabular}


Table 2. The stressors with the highest score (3 or above) for each year of study

\begin{tabular}{|l|l|l|}
\hline Year & Stressor (Domain) & Mean (SD) \\
\hline 1 DHDT & Fear of failing course/year (Academic) & $3.61(0.77)$ \\
\hline & Examinations (Academic) & $3.28(1.07)$ \\
\hline & Fear of being able to catch up if falling behind (Academic) & $3.06(1.21)$ \\
\hline & & \\
\hline 2 DHDT & Examinations (Academic) & $3.28(1.07)$ \\
\hline & & $3.50(0.73)$ \\
\hline 3 DHDT & Fear of failing course/year (Academic) & $3.38(0.80)$ \\
\hline & Examinations (Academic) & $3.06(1.12)$ \\
\hline & Fear of being able to catch up if falling behind (Academic) & $3.06(0.92)$ \\
\hline & Difference in opinion between clinical staff (Clinical) & \\
\hline & & $3.16(0.83)$ \\
\hline
\end{tabular}


Table 3. Dimensions of SPWB mean scores for DHDTs and DS

\begin{tabular}{|l|l|l|l|}
\hline $\begin{array}{l}\text { SPWB dimension } \\
\text { (MAX SCORE }= \\
84)\end{array}$ & $\begin{array}{l}\text { Mean (SD) } \\
\text { DHDT }(n=53)\end{array}$ & $\begin{array}{l}\text { Mean (SD) } \\
\text { DS ( } n=55)\end{array}$ & $p$ value \\
\hline Autonomy & $55.80(7.85)$ & $53.83(5.75)$ & 0.079 \\
\hline $\begin{array}{l}\text { Environmental } \\
\text { mastery }\end{array}$ & $57.22(7.24)$ & $54.20(4.52)$ & 0.007 \\
\hline Personal growth & $64.73(5.89)$ & $55.13(4.22)$ & $0.000^{*}$ \\
\hline $\begin{array}{l}\text { Positive relations } \\
\text { with others }\end{array}$ & $59.50(7.87)$ & $55.03(5.52)$ & $0.000^{*}$ \\
\hline Purpose in life & $61.62(8.51)$ & $49.58(4.85)$ & $0.000^{*}$ \\
\hline Self-acceptance & $57.01(9.92)$ & $53.05(5.23)$ & $0.000^{*}$ \\
\hline
\end{tabular}

* Bonferroni correction $p<0.002$ 
Table 4. Mean scores of DASS-21, AHS and VQ for DHDTs and DS

\begin{tabular}{|l|l|l|l|}
\hline $\begin{array}{l}\text { DASS-21, AHS and } \\
\text { VQ subscales (max } \\
\text { score within each } \\
\text { subscale) }\end{array}$ & $\begin{array}{l}\text { DHDT } \\
(\mathrm{n}=58) \\
\text { Mean (SD) }\end{array}$ & $\begin{array}{l}\text { DS } \\
(\mathrm{n}=68) \\
\text { Mean (SD) }\end{array}$ & $p$ value \\
\hline DASS-21 & & & \\
\hline Depression (42) & $7.26(8.01)$ & $4.94(6.50)$ & 0.052 \\
\hline Anxiety (42) & $8.0(7.73)$ & $5.14(5.53)$ & 0.035 \\
\hline Stress (42) & $12.20(8.99)$ & $7.79(6.57)$ & 0.004 \\
\hline & & & \\
\hline AHS & & & \\
\hline Agency (32) & $24.85(4.97)$ & $24.03(4.66)$ & 0.291 \\
\hline Pathway (32) & $23.2294 .89)$ & $24.23(4.58)$ & 0.180 \\
\hline & & & \\
\hline VQ & & & \\
\hline Progress (30) & $19.51(6.73)$ & $18.31(5.7)$ & 0.208 \\
\hline Obstruction (30) & $9.96(7.01)$ & $9.33(6.28)$ & 0.650 \\
\hline
\end{tabular}


Figure 1. Dental Environment Stress questionnaire items and domains

\begin{tabular}{|c|c|}
\hline DES Individual item stressor & Domain \\
\hline $\begin{array}{l}\text { Moving away from home } \\
\text { Environment in which to study } \\
\text { Lack of home atmosphere } \\
\text { Other problems with accommodation }\end{array}$ & Living accommodation \\
\hline $\begin{array}{l}\text { Making friends } \\
\text { Financial responsibilities } \\
\text { Personal physical health } \\
\text { Intimate Relationships } \\
\text { Necessity to postpone marriage } \\
\text { Necessity to postpone children } \\
\text { Having multiple roles } \\
\text { Conflict with spouse/mate over career development } \\
\text { Lack of time for relaxation } \\
\text { Having children in the home } \\
\text { Having reduced holidays compared with other students } \\
\text { Fear of going out due to crime } \\
\text { Dependencies (e.g. drugs, alcohol) }\end{array}$ & Personal factors \\
\hline $\begin{array}{l}\text { Expectation versus reality of dental school } \\
\text { Approachability of staff } \\
\text { Criticism about academic or clinical work } \\
\text { Rules and regulations of the dental school } \\
\text { Discrimination due to race, nationality, gender or social } \\
\text { class }\end{array}$ & $\begin{array}{l}\text { Educational } \\
\text { environment }\end{array}$ \\
\hline $\begin{array}{l}\text { Amount of assigned course work } \\
\text { Difficulty of course work } \\
\text { Fear of being able to catch up if falling behind } \\
\text { Competition for grades } \\
\text { Fear of failing course or year } \\
\text { Uncertainty about dental career } \\
\text { Examinations } \\
\text { Lack of input in decision making process in dental school }\end{array}$ & Academic work \\
\hline $\begin{array}{l}\text { Concerns about manual dexterity } \\
\text { Transition from preclinical to clinical } \\
\text { Learning precision manual skills } \\
\text { Completing clinical requirements } \\
\text { Concern about treatment grades awarded } \\
\text { Difference in opinion between clinical staff concerning } \\
\text { treatment } \\
\text { Shortage of allocated clinical time } \\
\text { Patient management } \\
\text { Confidence in own clinical decision making }\end{array}$ & Clinical factors \\
\hline
\end{tabular}


Figure 2. Cut-off scores for DASS - 21 severity labels (normal, moderate, severe) ${ }^{33}$

\begin{tabular}{|l|l|l|l|}
\hline & Depression & Anxiety & Stress \\
\hline Normal & $0-9$ & $0-7$ & $0-14$ \\
\hline Mild & $10-13$ & $8-9$ & $15-18$ \\
\hline Moderate & $14-20$ & $10-14$ & $19-25$ \\
\hline Severe & $21-27$ & $15-19$ & $26-33$ \\
\hline Extremely severe & $28+$ & $20+$ & $34+$ \\
\hline
\end{tabular}

